\title{
The role of stem cell therapy in regeneration of dentine-pulp complex: a systematic review
}

\author{
Hengameh Bakhtiar ${ }^{1,2}$ - Amir Mazidi $S^{3} \cdot$ Saeed Mohammadi Asl ${ }^{3} \cdot$ M. R. Ellini $i^{1,3} \cdot$ A. Moshiri $^{4} \cdot$ M. H. Nekoofar ${ }^{5}$. \\ P. M. H. Dummer ${ }^{6}$
}

Received: 12 August 2018 / Accepted: 12 September 2018 / Published online: 28 September 2018

(C) The Author(s) 2018

\begin{abstract}
Infection of the dental pulp will result in inflammation and eventually tissue necrosis which is treated conventionally by pulpectomy and root canal treatment. Advances in regenerative medicine and tissue engineering along with the introduction of new sources of stem cells have led to the possibility of pulp tissue regeneration. This systematic review analyzes animal studies published since 2010 to determine the ability of stem cell therapy to regenerate the dentine-pulp complex (DPC) and the success of clinical protocols. In vitro and human clinical studies are excluded and only the experimental studies on animal models were included. Dental pulp stem cells constitute the most commonly used cell type. The majority of stem cells are incorporated into various types of scaffold and implanted into root canals. Some of the studies combine growth factors with stem cells in an attempt to improve the outcome. Studies of ectopic transplantation using small animal models are simple and non-systematic evaluation techniques. Stem cell concentrations have not been so far reported; therefore, the translational value of such animal studies remains questionable. Though all types of stem cells appear capable of regenerating a dentine-pulp complex, still several factors have been considered in selecting the cell type. Co-administrative factors are essential for inducing the systemic migration of stem cells, and their vascularization and differentiation into odontoblastlike cells. Scaffolds provide a biodegradable structure able to control the release of growth factors. To identify problems and reduce costs, novel strategies should be initially tested in subcutaneous or renal capsule implantation followed by root canal models to confirm results.
\end{abstract}

Keywords Stem cell therapy $\cdot$ Dentin-pulp complex $\cdot$ Dentinogenesis $\cdot$ Tissue engineering $\cdot$ Regenerative medicine

Hengameh Bakhtiar

hengamehbakhtiar@gmail.com; h_bakhtiar@dentaliau.ac.ir

Amir Mazidi S

amir.mazidi@ymail.com

Saeed Mohammadi Asl

dj_saeed72@yahoo.com

M. R. Ellini

ellini.mr@gmail.com

A. Moshiri

dr.ali.moshiri@gmail.com

M. H. Nekoofar

nekoofar@yahoo.com

P. M. H. Dummer

dummer@cardiff.ac.uk

1 Endodontic Department, Dental Material Research Center, Tehran Dental Branch, Islamic Azad University, Tehran, Iran
2 Stem Cell Research Center, Central Tehran Branch, Islamic Azad University, No. 4, 10th Neyestan St., Pasdaran Ave, Tehran, Iran

3 Student Research Committee, Islamic Azad University, Tehran branch, No. 4, 10th Neyestan St., Pasdaran Ave, Tehran, Iran

4 Department of Orthopedic Surgery, School of Medicine, AJA University of Medical Science, West Fatemi St, Etemadzadeh St, Tehran, Iran

5 Department of Endodontics, School of Dentistry, Tehran University of Medical Sciences, North Karegar St, P.O. Box: 14395-433, Tehran 14399-55991, Iran

6 Endodontology Research Group, School of Dentistry, College of Biomedical and Life Sciences, Cardiff University, Heath Park, Cardiff CF14 4XY, UK 


\section{Introduction}

As a consequence of caries, periodontal disease, trauma and several iatrogenic factors (Aksel and Serper 2014; Nagaveni et al. 2015), the human dentine-pulp complex (DPC) can develop reversible pulpitis that will progress to irreversible pulpitis and pulp necrosis without treatment. Currently, when the pulp is not savable, root canal treatment (RCT) is advised (Gong et al. 2016). Although RCT may be a successful option, the treated root canal system can become re-infected and/or the root may become susceptible to fracture ( $\mathrm{Li}$ et al. 2016) leading either to the loss of the tooth or expensive and complex alternative treatments such as root canal retreatment, surgery, implants, etc.

Regenerative endodontics (RE) is a relatively new component of tissue engineering and regenerative medicine, which aims to introduce alternative options to classical treatment strategies ( $\mathrm{Na}$ et al. 2013). The goal in RE is to replace the necrotic pulp with scaffolds, healing promoting factors, and cell therapies with the aim of regenerating new pulp and dentine within the root canal system (Galler et al. 2011). Different innovative methods including platelet concentrates (Bakhtiar et al. 2017a; Fakhr Tabatabayi et al. 2015) and treated dentine matrix (Bakhtiar et al. 2017b) products and stem cells have been used for this purpose. In this respect cell therapy is an important part of RE (Brar and Toor 2012; Rodriguez-Lozano et al. 2012) and various forms of stem cells may be utilized in order to provide the cells necessary for the regeneration of both the dentine and pulp (Alongi et al. 2010; Cao et al. 2015). The transplanted cells should be differentiated into various lineages including fibroblast, nerve cells, endothelial cells and odontoblasts to form new connective tissue, nerve fibers, blood vessels, and dentine (Shi et al. 2005). Thus, regeneration of the dentine-pulp complex is a complicated process (Schmalz and Smith 2014).

Because fully differentiated cells are aged and have low viability and limited matrix production soon after transplantation (Stolzing et al. 2008), stem cells are used as an alternative (Murakami et al. 2015) (Tables 1, 2, 3, 4 and 5). Stem cells have a number of advantages compared with differentiated cells (Murray et al. 2007), for example, they preserve their self-renewal capacity after transplantation and can be induced to differentiate into various cells lineages to be useful for regeneration of the dentine-pulp complex (Eslaminejad et al. 2007). Stem cells are classified into embryonic stem cells (Hilkens et al.), induced Pluripotent stem cells (iPSC) and adult/postnatal stem cells (Nuti et al. 2016). IPSCs and ESCs have received limited attention because of technical difficulties, ethical concerns and greater risk of carcinogenesis (Murray

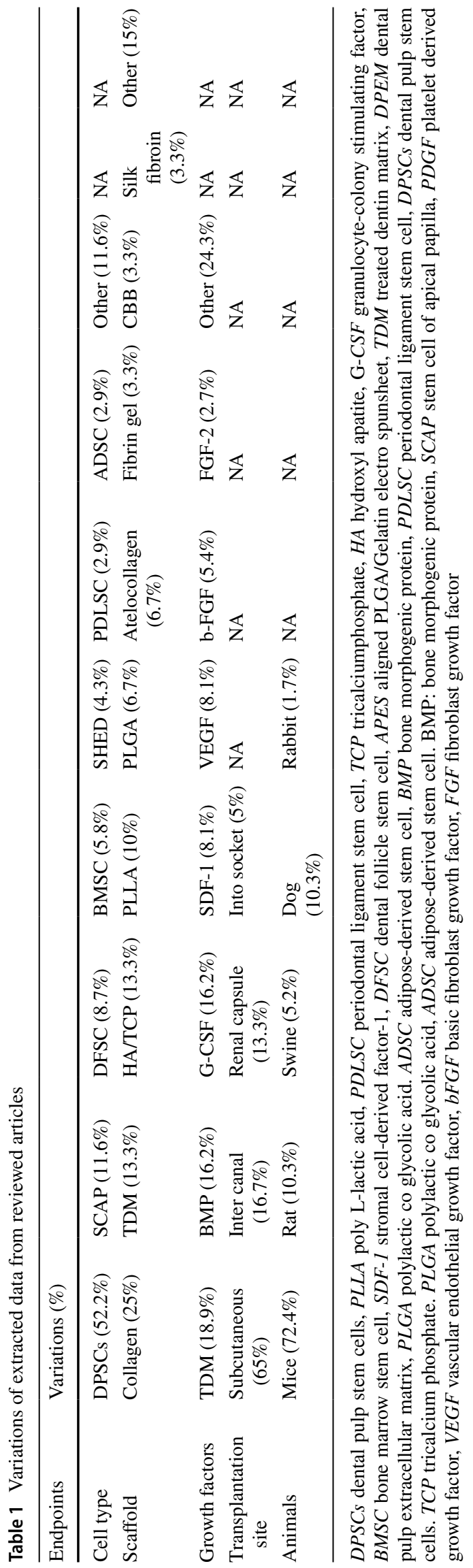




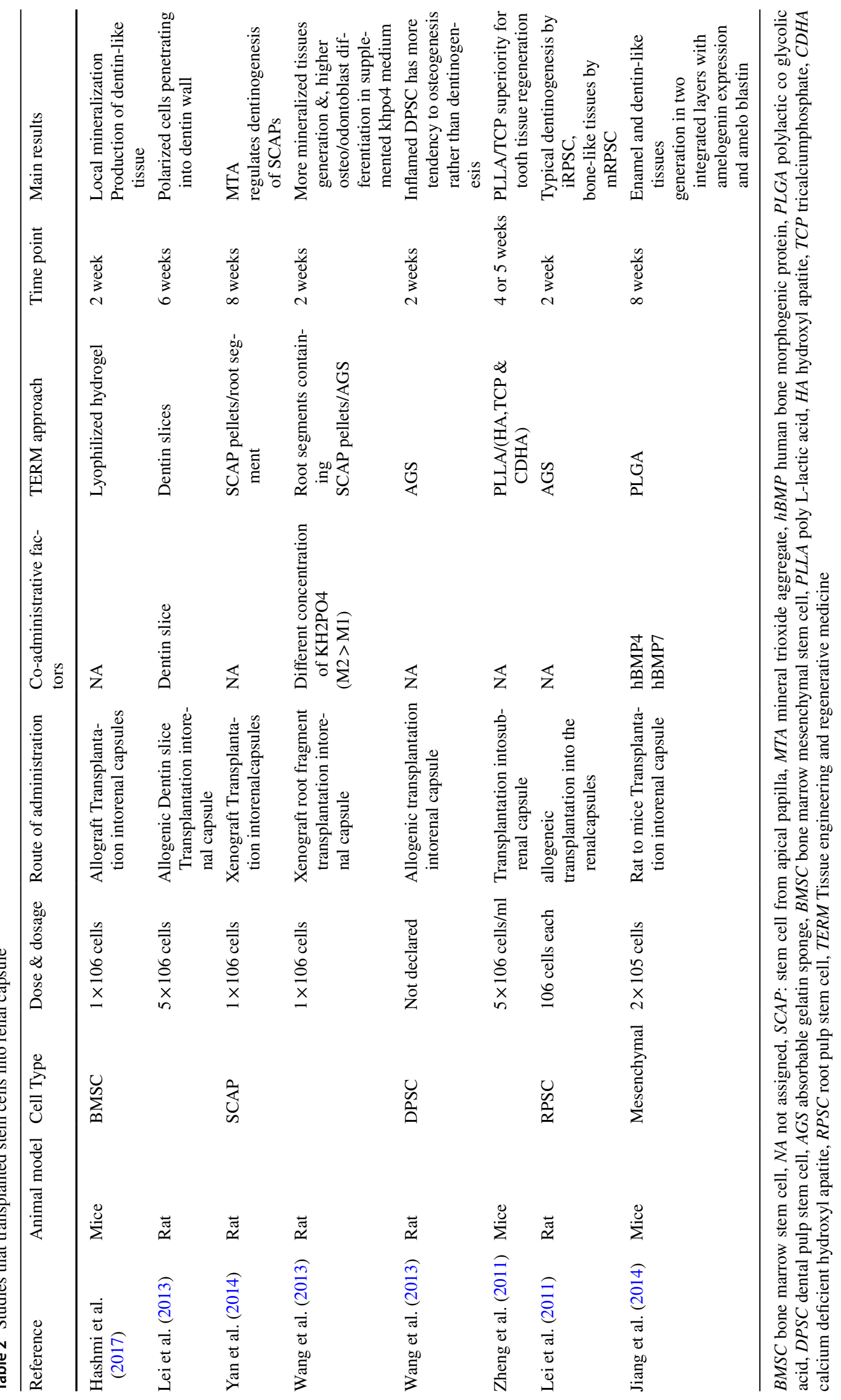




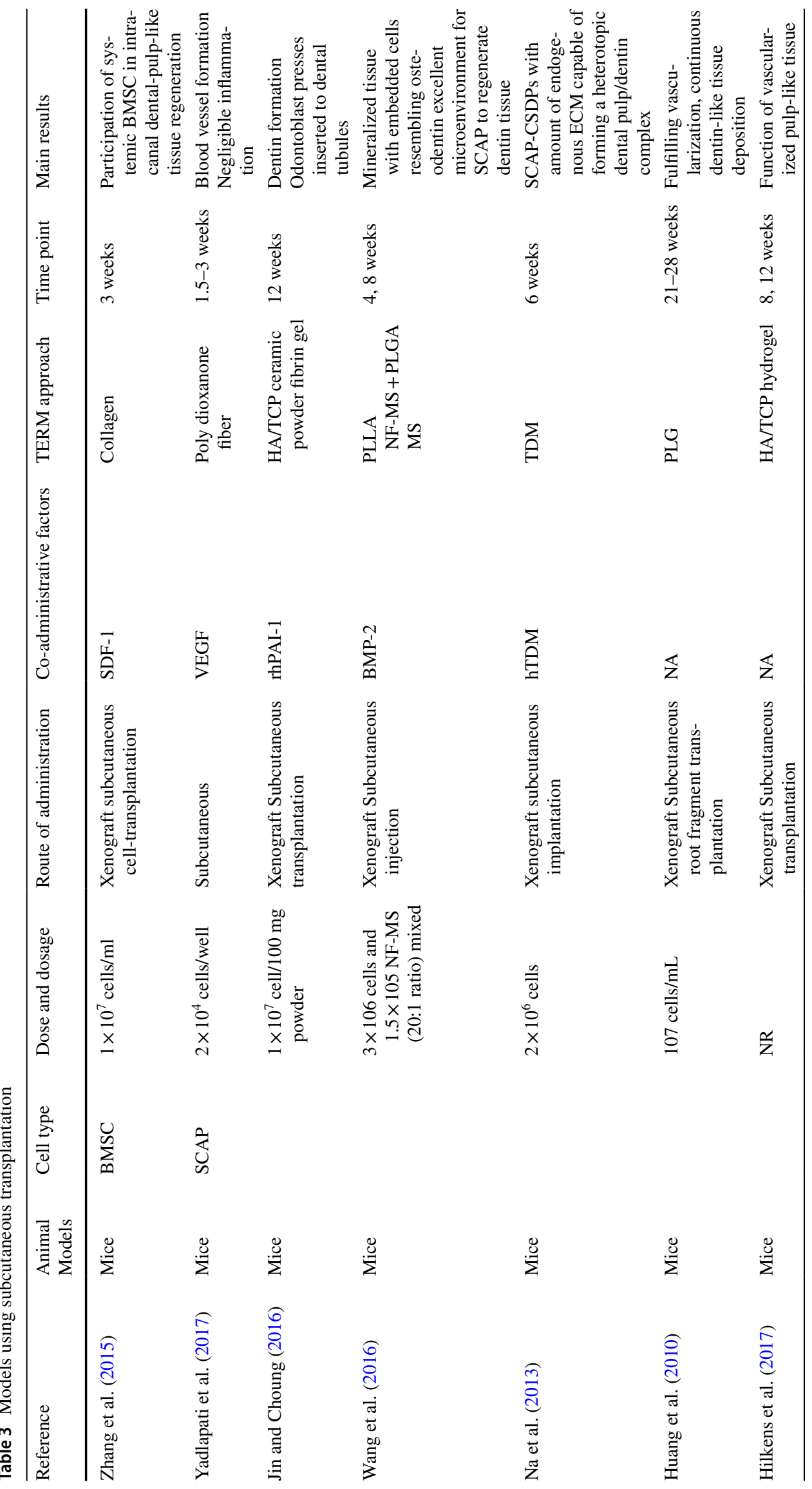




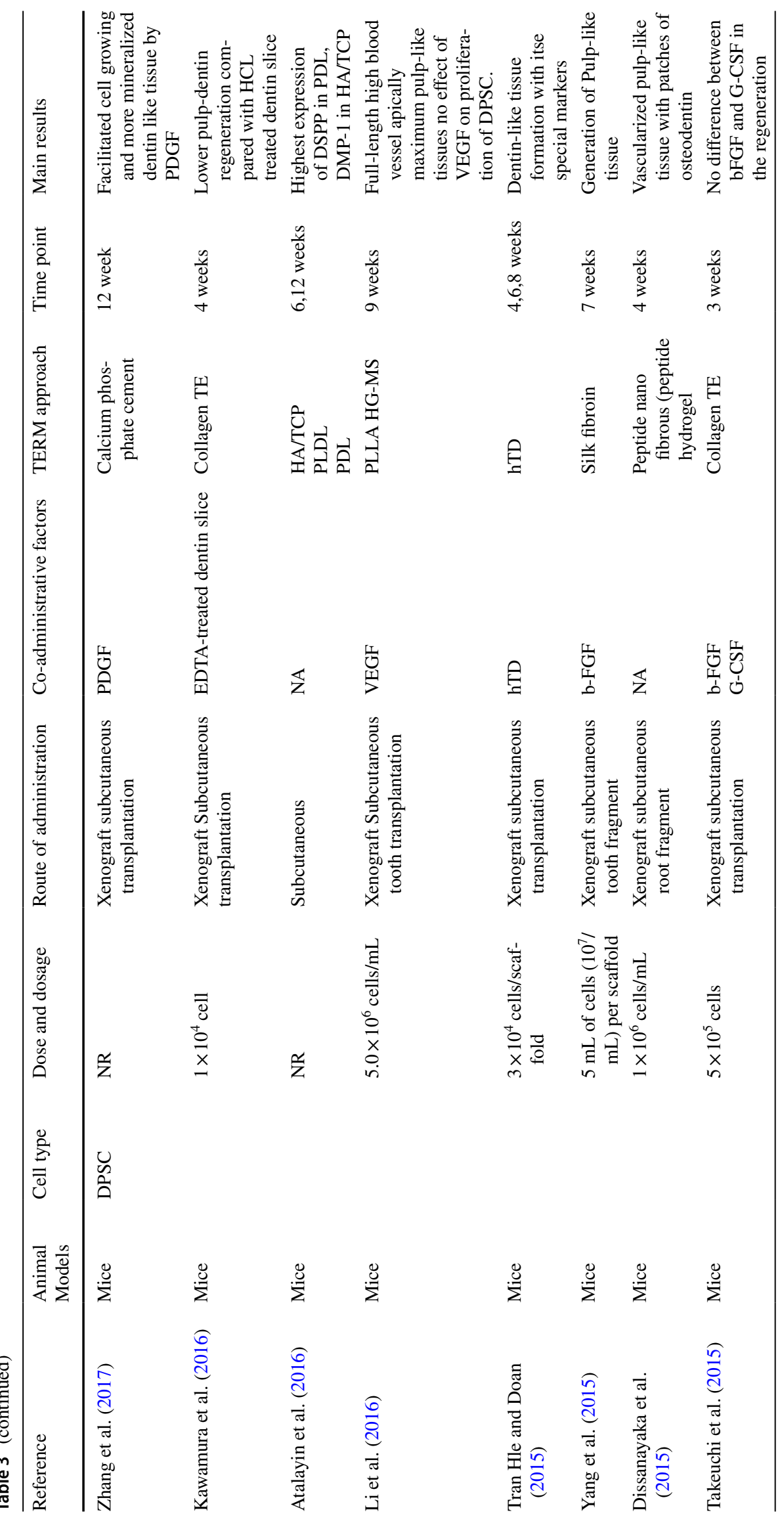




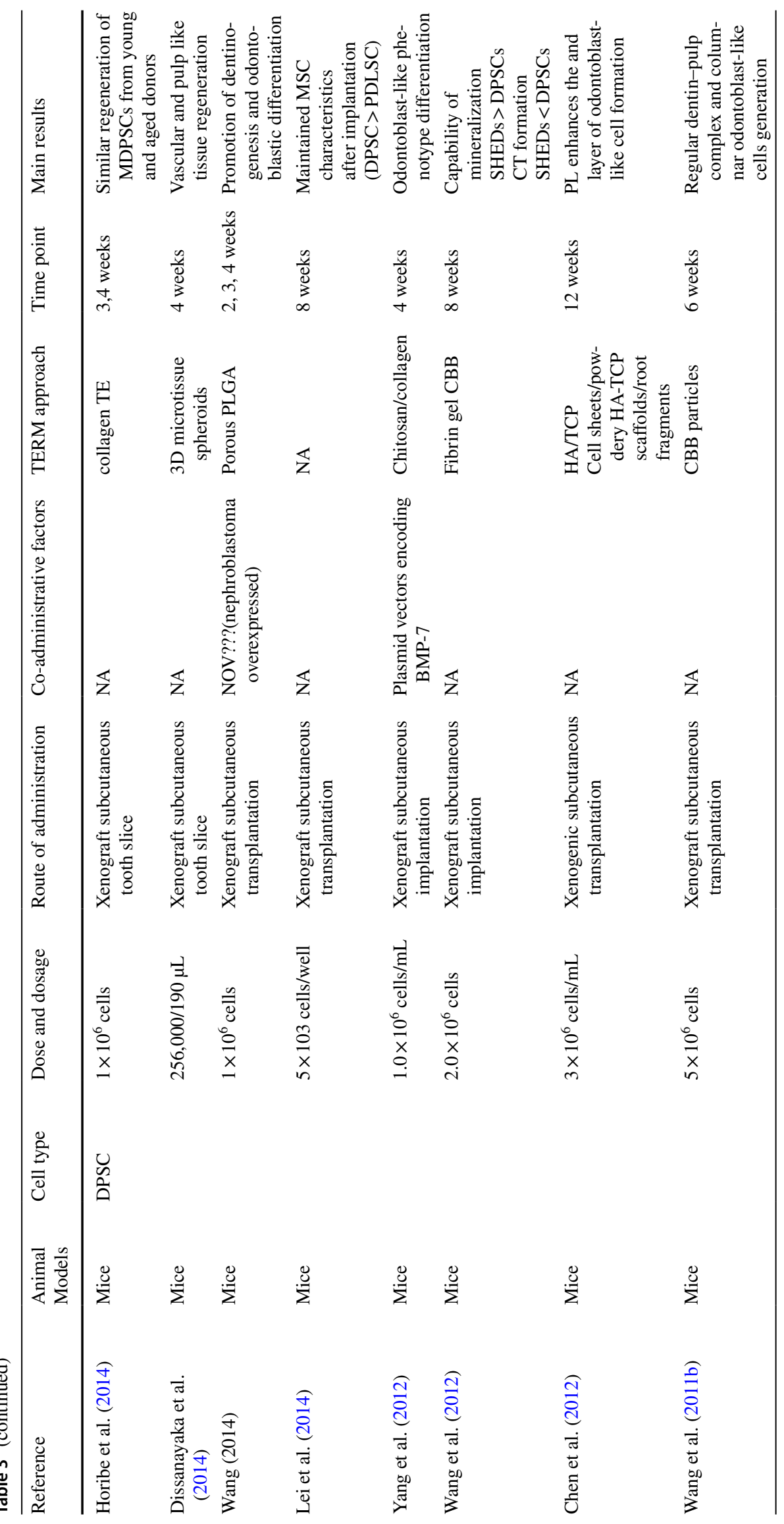

Springer 


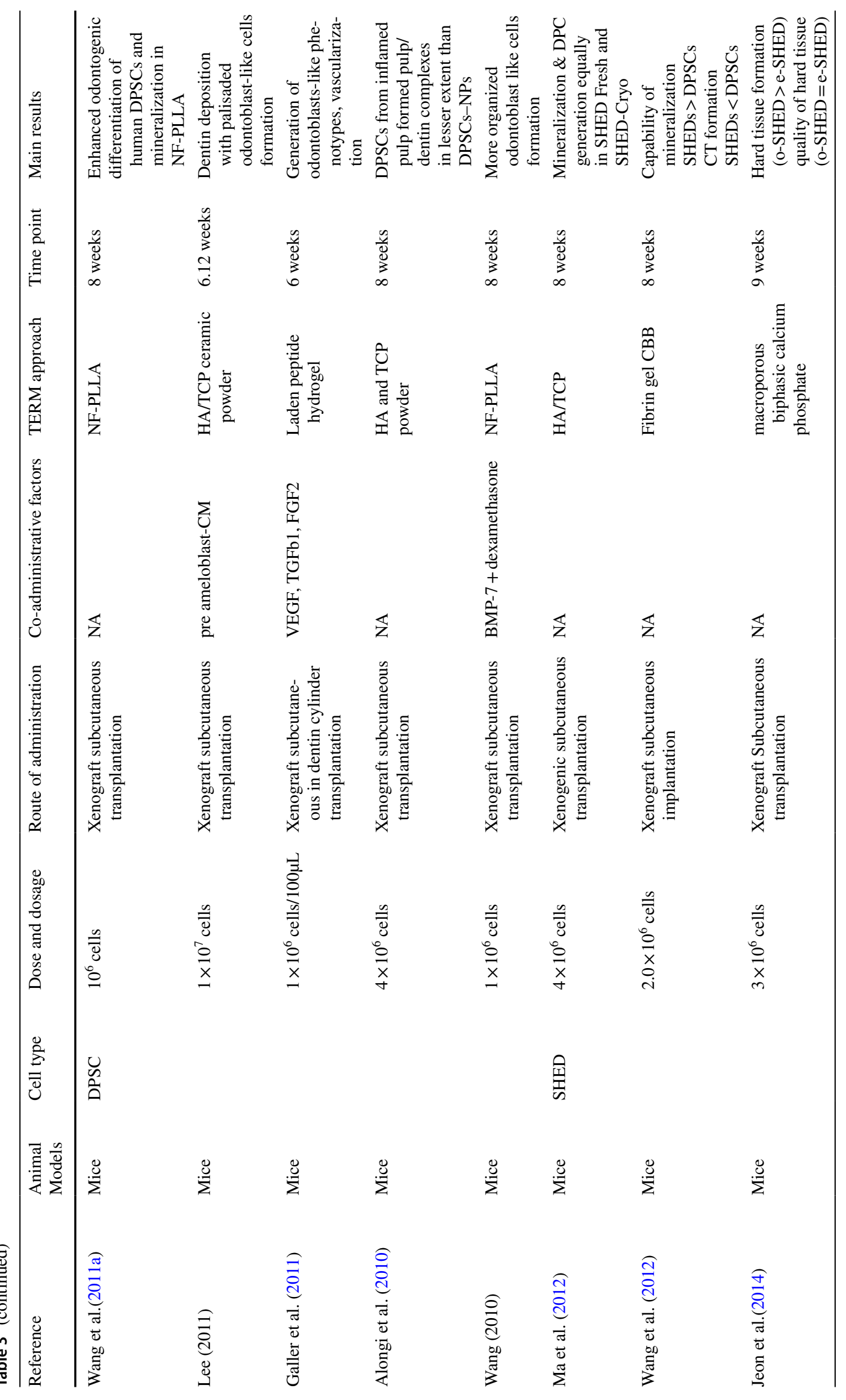




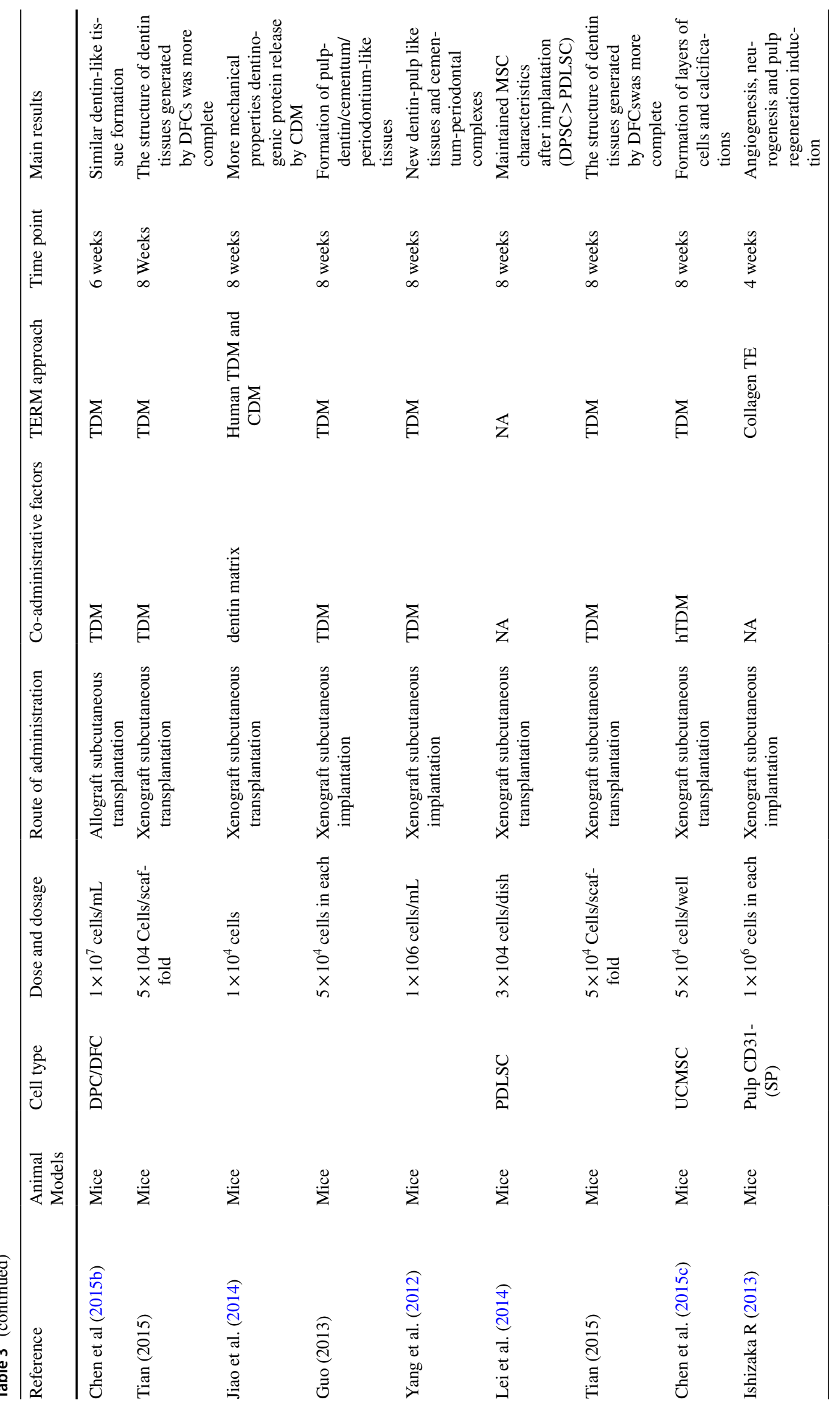

4 Springer 


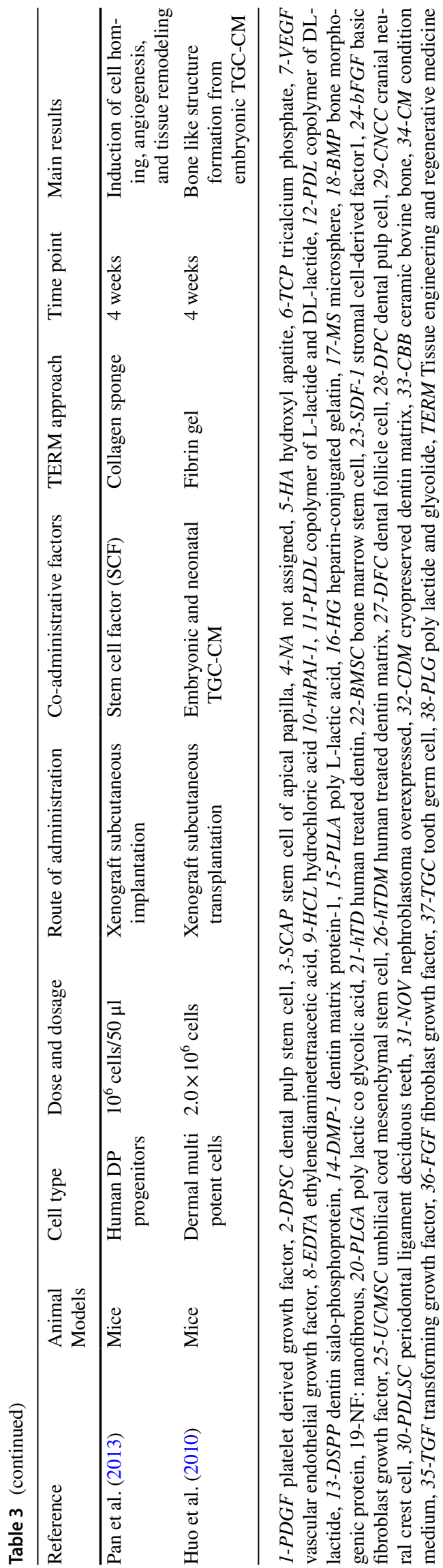

et al. 2007). Thus, studies on stem cells have concentrated on adult mesenchymal stem cells (Devolder 2010). Even though adult/postnatal stem cells have lower capacity for differentiation compared with ESCs and iPSCs, they can be used as a source of autologous grafting during an entire life (Casagrande et al. 2011).

Many sources of adult/postnatal stem cells have been investigated in the mouth including the dental pulp, periodontal ligament (PDL), dental follicle, gingiva, bone, alveolar bone, and papilla (Egusa et al. 2012). Among these, dental pulp stem cells (DPSCs) are easiest to access; they also have a greater differentiation capacity and are widely used in dental research (Nuti et al. 2016). Furthermore, adult/postnatal stem cells can remain undifferentiated when they are not exposed to differentiating signaling molecules (Schmalz and Smith 2014), are capable of long term self-replication, and maintain their capacity for multiple differentiation during the entire life of organs (Barry 2003).

The developing science of stem cells has succeeded in regenerating parts of the heart (Chong and Murry 2014), muscles (Dellavalle et al. 2011), bone (Asatrian et al. 2015) and the nervous system (Reynolds and Weiss 1992). Such developments have also included oral and dental tissues (Ikeda et al. 2009). For example, stem cells have been used for regeneration of the periodontium, alveolar bone, dentinepulp complex, craniofacial bone, mucosal tissue, tongue muscle, and for returning the function of salivary glands (Liu and Cao 2010; Rimondini and Mele 2009). Because of complications with whole tooth regeneration, substantial efforts have been made to regenerate the dentine-pulp complex (Gao et al. 2016). Although adult/postnatal stem cells therapy has been the focus of many studies, a lack of consensus on the actual efficacy of adult/postnatal stem cells for dentine-pulp regeneration, has constrained its clinical value.

This study was designed to evaluate in vivo animal studies that have used adult/postnatal stem cells to determine whether adult/postnatal stem cells therapy is able to regenerate new dentine-pulp complexes and which of the many available protocols can be translated into the clinical setting. Therefore, laboratory and human clinical studies were excluded.

\section{Review}

\section{Search strategy}

English scientific reports published since 2010 and indexed in PubMed were searched. The main key terms included: "stem cell", "dentin-pulp complex", "dentinogenesis" and "pulp regeneration". Because regeneration of the dentinepulp complex must be evaluated in vivo and since most of the studies are performed in animal models, the in vitro and 
Table 4 Models that transplanted stem cells into the jawbone or extracted socket

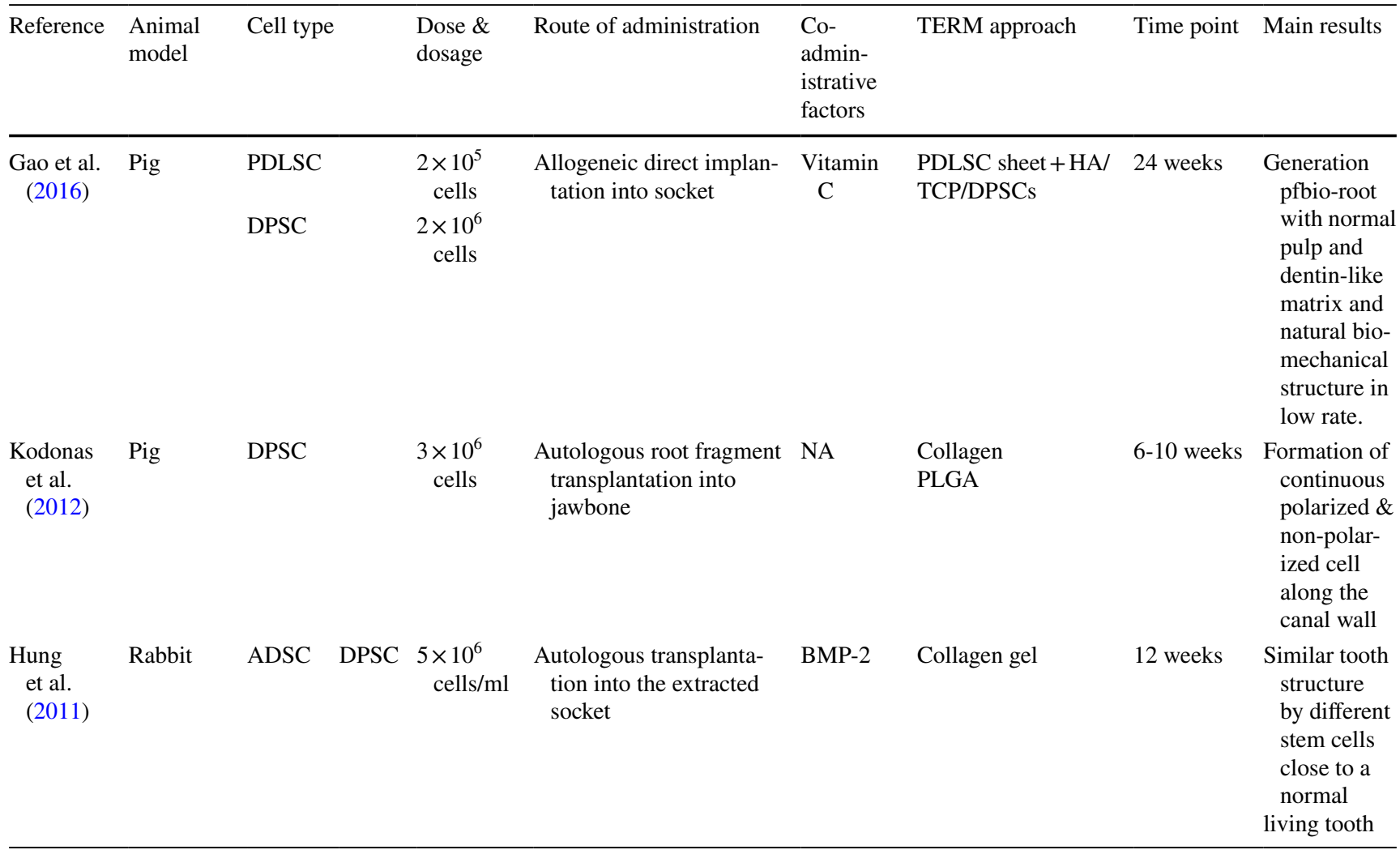

1-PDLSC periodontal ligament stem cell, 2-DPSC dental pulp stem cell. 3-HA hydroxyapatite, 4-TCP: tricalcium phosphate. 5-PLGA polylactic co glycolic acid, 6-ADSC adipose-derived stem cell, 7-BMP bone morphogenic protein, TERM Tissue engineering and regenerative medicine

human clinical studies were excluded and only experimental studies on animal models were included in the present review. Specific aspects of the studies including animal models, type of stem cells used for pulp regeneration and their sources, concentration of the administered cells, route of administration, co-administrative factors, tissue engineering approaches of the cell therapy, time point evaluation of the regeneration process and the main result of each study were reviewed and evaluated to allow comparisons. Overall, 1490 articles which were identified in our search included; unrelated articles, in vitro cases, studies with bone regeneration approaches; by excluding review articles; and finally, 60 studies that focused on the role of adult/postnatal stem cell therapies for regeneration of the dentine-pulp complex in animal models were included (Fig. 1).

\section{Types of stem cells}

All the stem cells used for dentine-pulp regeneration were adult mesenchymal stem cells (MSCs); however, the source of harvesting the MSCs varied in different studies. Dental pulp stem cells (DPSCs) were the first dental stem cells to be isolated and their odontogenic, neurogenic, and angiogenic properties were reported in several studies (Dissanayaka et al. 2015; Kuang et al. 2016; Wang et al. 2013). These cells were capable of being harvested during the early stages of life and were stored for future use (Tran Hle and Doan 2015). The majority (52\%) of the studies used DPSCs for regeneration of dentine-pulp complexes (Tables 1, 2, 3, 4 and 5).

Among the 60 studies reviewed 36 cases used DPSCs (Tables 2, 3, 4 and 5). Of the 8 studies that transplanted stem cells into the renal capsule, 2 cases used DPSCs (Table 2). In 39 studies of subcutaneous transplantation, 25 of them used DPSCs (Table 3). Of the 10 studies with intracanal transplantation, seven used DPSCs (Table 5). Of the 60 studies that were reviewed, 8 used SCAPs (Table 1, 2, 3, 4 and 5). In two studies the cells were transplanted into the renal capsule (Table 2) and six of the studies transplanted the cells subcutaneously (Table 3 ). No studies used SCAPs transplanted into root canals (Table 5). In the evaluated studies, 2 studies attempted to regenerate PDL tissue by means of PDLSCs, one transplanted subcutaneously and one transplanted into an extraction socket (Tables 3 and 4). In total 3 studies used SHEDs and all used a subcutaneous approach (Table 3). Three studies used BMSC, 2 in the renal capsule, 1 subcutaneously and the other was transplanted in a root canal (Tables 2, 3 and 5). Only Chen et al. (2015c) 


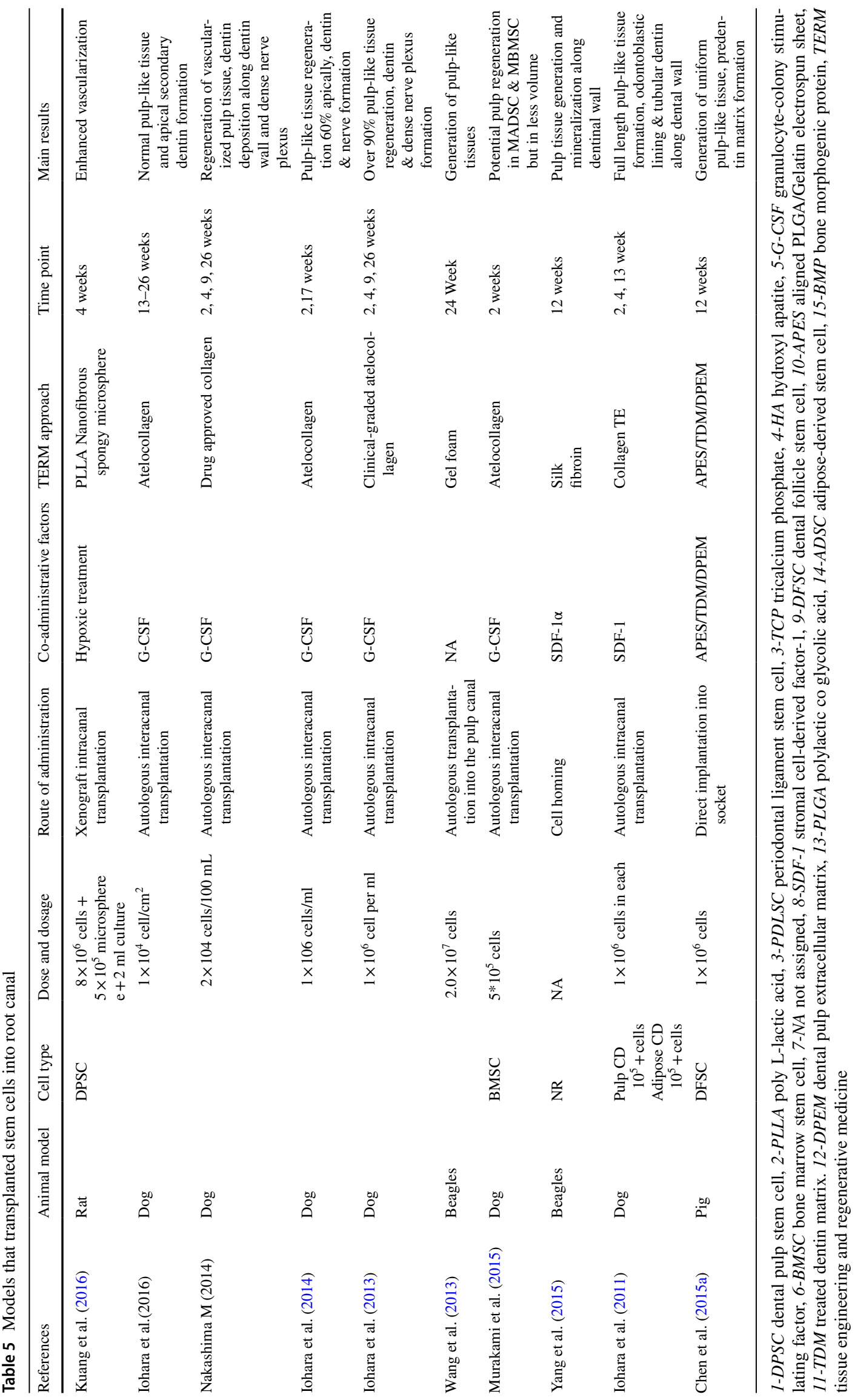


Fig. 1 Search strategy

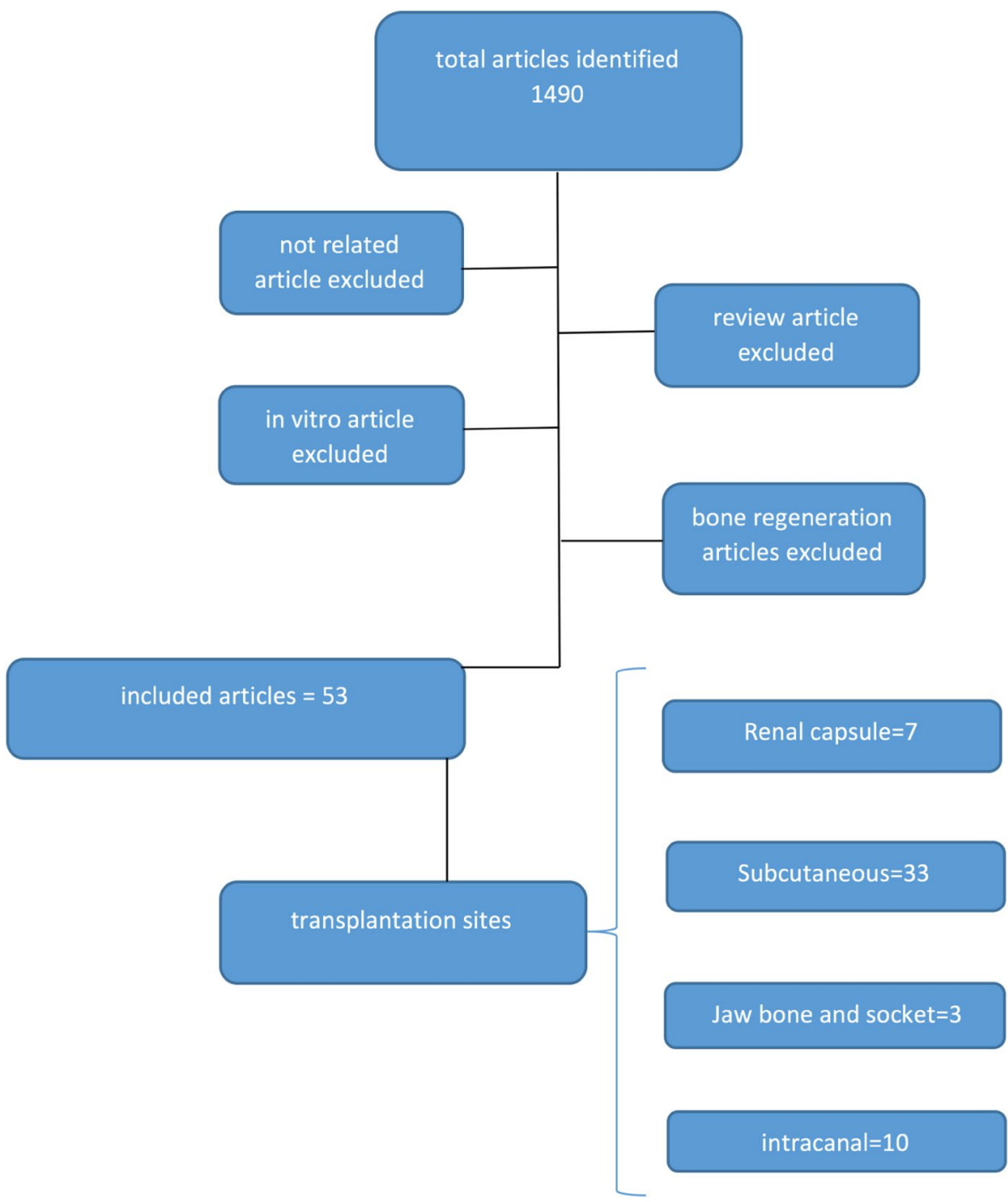

transplanted UCMSC subcutaneously (Table 3). Of the 60 studies evaluated, 9 used autologous stem cells (Tables 2, 3, 4 and 5). None of the studies with a renal or subcutaneous transplantation approach used autologous stem cells (Table 2 and 3). One subcutaneous transplantation case and one renal capsule model used allograft stem cells and the rest (47 out of 49 studies) used xenograft stem cells (Table 3 ).

\section{Dental pulp stem cells}

In all studies using DPSCs, they isolated the stem cells from human healthy pulp tissue to be used in their animal model, usually from orthodontically extracted teeth, for instance third molars were often used (Chen et al. 2012). Alongi et al. (2010) reported that inflamed pulp tissue was an appropriate source for isolation of DPSCs. In their study inflamed pulp-derived stem cells revealed a capacity for regeneration of the dentine-pulp complex, albeit the regeneration was weaker compared with the control group where the cells were derived from intact pulps (Alongi et al. 2010). It has also been reported that stem cells from an exposed pulp are more prone to differentiate into osteoblastic cells rather than dentinogenic cells (Wang et al. 2013).

\section{Stem cells from apical papilla}

As an element of a developing tooth, the stem cells of the apical papilla (SCAP) have a greater stem capacity (Huang et al. 2010; Wang et al. 2016). Stem cells of the apical papilla are known for more rapid proliferation and mineralization, better migration and telomerase activity than DPSCs (Huang et al. 2010). Wang et al. (2016) reported deposition of more uniform dentine-like tissue created by SCAPs than DPSCs with greater similarities to natural dentine. Stem cells of the apical papilla were commonly isolated from immature third molars. 


\section{Periodontal ligament stem cells}

Periodontal ligament stem cells (PDLSCs) have been used to create PDL (periodontal ligament) in studies attempting to regenerate a new bio-root (Gao et al. 2016). They achieved a bio-root with a suitable PDL tissue using a combination of DPSCs and hydroxyapatite, which were wrapped by a sheet of PDLSCs. These newly generated roots in miniature pigs, had similar qualities to natural teeth in both mineral component and biomechanical properties but successful results were achieved in only one-fifth of the samples while titanium implants were $100 \%$ successful (Gao et al. 2016).

\section{Stem cells from human exfoliated deciduous teeth}

Stem cells from human exfoliated deciduous teeth (SHED) are another type of stem cell, which are derived from extracted deciduous teeth and are considered as a non-invasive source of stem cells (Jeon et al. 2014). These stem cells have an enhanced capacity for osteogenic regeneration and higher proliferation rate compared with DPSCs (Wang et al. 2012).

\section{Bone marrow derived mesenchymal stem cells}

Bone marrow derived mesenchymal stem cells (BM-MSCs) are another source that has been used extensively in regenerative procedures (Lei et al. 2013). Use of such cells with a dentine matrix scaffold was associated with differentiation of the stem cells into polarized odontoblast-like cells with penetrating processes into dentinal tubules (Lei et al. 2013). However, harvesting these cells from human sources is an invasive procedure and its main clinical application is in orthopedic research (Chen et al. 2015d). Meanwhile, Zhang et al. (2015) suggested the use of endogenous BM-MSC for regenerating lost tissue after observing its systemic homing to the root canal, powered by application of stromal cellderived factor-1 (SDF-1), in a subcutaneously transplanted tooth with a root canal.

\section{Adipose-derived stem cells}

Hung et al. (2011) used adipose-derived stem cells (ADSCs) due to their large population in mammals and higher rate of proliferation with similar results to DPSCs in tooth regeneration. While harvesting DPSCs is achieved primarily from the healthy pulp of a tooth, use of ADSCs could be more convenient. Murakami et al. (2015) reported that despite the superiority of DPSCs, sufficient ADSCs and bone marrow derived mesenchymal stem cells could be considered as an alternative to DPSCs.

\section{Umbilical cord mesenchymal stem cells}

Umbilical cord mesenchymal stem cells (UCMSC) are available in large volumes without invasive harvesting procedures and are stored in worldwide stem cell banks (Chen et al. 2015c). They reported UCMSC capacity for differentiation into odontoblast-like cells and deposition of hard tissue. Notably, these cells are considered safe as they are protected from viral infections by the placenta, which has a significant clinical importance (Chen et al. 2015c).

\section{Sources of stem cell}

Although using autologous stem cell grafts are a priority and conforms to regulatory policies, there are limitations for harvesting autologous stem cells in elderly patients (Wei et al. 2013). This study reported a promising capacity for using allograft stem cells for tooth regeneration in their studies on miniature pigs for developing a bio-root.

Before administering stem cells for regeneration, they need to be cultured to achieve the required quantity, especially when considering human derived stem cell due to their limited numbers (Asatrian et al. 2015; Chen et al. 2012; Dissanayaka et al. 2014). Traditionally, cell culturing is undertaken with fetal bovine serum, which increases the risk of transinfection and immunologic responses (Chen et al. 2012). Researchers have used human platelet lysate for cell culturing during pulp tissue regeneration, implying that the use of autologous medium is a possibility (Chen et al. 2012). Besides increasing the quantity of the stem cells, culturing stem cells with different vehicles can induce them to differentiate into specific target tissues. For instance, dexamethasone and ascorbic acid in culture media lead to greater osteogenic differentiation (Wang et al. 2013). Tooth germ cell-condition medium (TGC-CM) has been introduced for its inductive properties in odontoblastic differentiation (Huo et al. 2010), which can be prepared from three sources: human, rat and porcine. Wang et al. (2011b) reported that culturing DPSCs using porcine-derived TGC-CM resulted in greater regular odontoblast-like cell layer formation compared with human-derived TGC-CM. Huo et al. (2010) prepared TGC-CM from rats in two stages, embryonic and neonatal, and cultured dermal multipotent stem cells in these two media. They observed that embryonic TGC-CM was more bone inductive rather than odontoblastic (Huo et al. 2010). In mineralization-inductive media, supplementary amounts of $\mathrm{KH}_{2} \mathrm{PO}_{4}$ can make the stem cells more potent for odontoblast or osteoblast differentiation (Wang et al. 2011a, 2013). Only these two studies have used this culture medium in their subcutaneous transplantation models (Table 3). 


\section{Animal models}

Rodents were the most widely used animals (Tables 2, 3, 4 and 5), probably due to their genetic similarities to humans. In addition, rodents are cheaper with a more rapid rate of birth that makes them suitable for in vivo studies. Among rodents, the mice and rat were the most popular animal models used in large numbers probably because of their low cost, which led to. Rabbit was another animal that was used, but it was less popular and used less frequently. Pigs and dogs were also used. Among the 60 studies evaluated, 44 studies used mice as the animal model. All the 39 studies (100\%) involving a subcutaneous transplantation approach used mice (Table 3) whereas no study involving intracanal transplantation used mice except one study, which used rats (Table 5). From eight studies with transplantation into the renal capsule, three used mice and 5 used rats, thus mice and rats were the animals of choice for transplantation into the renal capsule (Table 2). Pig and rabbit were used as animal models in 3 studies where the transplantation was in the jawbone or the extraction socket (Table 4). Among 10 intracanal transplantation studies evaluated, all used dogs except for one (Kuang et al. 2016) that used rats.

\section{Route of administration}

Most of the studies on tooth slices, containing a root canal with overlying dentine as implantation of complete root structures in rodents, are challenging. Slices were then subcutaneously implanted in the dorsum of animals and the cells were either seeded within a form of scaffold or hydrogel in the centre of the slices corresponding to the root canal (Alongi et al. 2010; Dissanayaka et al. 2014, 2015; Horibe et al. 2014; Huang et al. 2010; Ishizaka et al. 2013; Lei et al. 2014; Takeuchi et al. 2015; Tran Hle and Doan 2015; Yan et al. 2014; Yang et al. 2015b; Zhang et al. 2015). However, tooth slices had variable thickness, which significantly affected the reliability of the studies.

The best environment that simulates the real situation is a pulpectomized canal of a tooth in the alveolus of an animal (Table 4) since this simulates better the human situation. In this way, because all clinically relevant factors are included, outcomes are more generalizable and conclusive. As stated, however, orthograde regenerative endodontic procedures with stem cells have been performed in few studies on larger animal models such as dogs. Of the 60 studies evaluated in the present review, 47 (78\%) used subcutaneous $(65 \%)$ or a renal capsule $(13 \%)$ implantation model in a retrograde manner while 10 studies $(22 \%)$ used an orthograde model (true root canal model $17 \%$ and into jaw bone or socket, $5 \%$ ).

\section{Tissue engineering and regenerative medicine approach (biomaterials)}

Scaffolds have a major role during cell therapy. In fact, most of the in vivo studies that administered stem cells for regeneration of the dentine-pulp complex used a type of scaffold combined with stem cells. Beside delivery of stem cells, carriers (scaffolds) also act as carriers for growth factors to control their release (Wang et al. 2016; Yang et al. 2012). Tissue scaffolds vary widely; based on their structure and architecture, they may be fibrous or spongy with variable pore size and porosity (Kuang et al. 2016). Based on the material properties, scaffolds may be natural, synthetic or hybrid with variable drug delivery, cell behavior, in vivo behavior and biophysicochemical properties (Ajay Sharma et al. 2015; Hilkens et al. 2014; Tran Hle and Doan 2015).

In designing suitable scaffolds for dentine-pulp regeneration they should mimic the native environment of the dentine-pulp area to trigger stem cells to differentiate into various cell lineages (Ajay Sharma et al. 2015; Chen et al. 2015a; Dissanayaka et al. 2014). In addition, an optimum scaffold should be porous (Kuang et al. 2016). Thus, spongy scaffolds may be the superior option since their greater porosity allows stem cells to migrate, proliferate and attach to the scaffold sheet as well as encourage the stem cells to synthesize a homogenous matrix (Kuang et al. 2016). Thus, such porous scaffold should have good porosity with large diameter interconnecting pores (Nagaveni et al. 2015; Wang et al. 2011a). Porous structures such as nanofibrous microspheres also make fewer by products after degradation due to their lower density compared with non-porous structures such as solid microspheres ( $\mathrm{Li}$ et al. 2016; Nagaveni et al. 2015; Wang et al. 2016). In addition, the scaffolds should be biocompatible and biodegradable in vivo (Sharma et al. 2014). An incompatible scaffold would trigger inflammation over a long period of time and a non-biodegradable or even slow biodegradable scaffold would retard new tissue ingrowth and prevent uniform matrix formation (Chan and Leong 2008).

A biomimetic scaffold for dentine-pulp regeneration should be a biphasic structure with a suitable medullary region for pulp regeneration and a cortical region suitable for dentine regeneration. Since the pulp area is chiefly composed of organic tissue the medullary element of such a biomimetic scaffold should be fabricated from organic materials such as gelatin, collagen, elastin, fibrin, etc. Because hydroxyapatite forms the greater percentage of dentine (Goldberg 2011), the outer cortical area of such a scaffold should be madeup of inorganic materials such as hydroxyapatite and tricalcium phosphate (Wang et al. 2013). To improve scaffold drug delivery and mechanical properties, small amounts of synthetic materials such as polylactic co glycolic acid (PLGA), polylactic acid (PLA), polycaprolactone (PCL) and 
polyglycolic acid (PGA) may be incorporated into the medullary and cortical regions of the desired scaffold as a basic mesh (Zheng et al. 2011). In addition, due to the irregular shape of pulp canals, injectable scaffolds with small particle sizes are desirable (Nagaveni et al. 2015).

After evaluating the 60 studies in the present review, of the 40 studies with transplantation into the renal capsule or subcutaneously, 8 used treated dentine matrix (TDM) and 10 used calcium/phosphate-containing compounds such as hydroxylapatite (HA) or tricalcium phosphate (TCP) as the carrier for stem cells whereas no study transplanted TDM into the renal capsule and only one study used calcium/ phosphate-containing compounds for renal capsule transplantation (Tables 2 and 3). Among the 60 studies, 6 used PLLA, four used PLGA, 15 used collagens, 2 used fibrin, 2 used fibroin and 1 used gel foam (Tables 2, 3, 4 and 5). Of 8 studies using renal capsule transplantation, 3 used absorbable gelatin sponge (AGS) and there was no use of AGS in the other three approaches (Table 2). On the other hand, no collagen was used in the renal capsule approach, whereas it was popular in other approaches (Table 2). Only 2 studies out of 60 used hydrogels and those were transplanted subcutaneously (Table 3 ). Only 1 study used microtissue cells without a carrier in subcutaneous transplantation (Table 3). The transplantation was accompanied with a slice of root or dentine in 3 studies with renal capsule transplantations and 1 study with subcutaneous transplantation (Tables 2 and 3).

\section{Dose}

Cell concentration is an important criterion when stem cell therapy is designed for dentine-pulp regeneration. There was a lack of significant strategy to estimate the dose of stem cells appropriate for dentine-pulp regeneration complex in these 60 studies. High doses of stem cells may have an inhibitory effect on regeneration as the nutrient supply of the pulp is restricted (Zheng et al. 2012). On the other hand, low doses of stem cells lead to less tissue generation. Further, scaffolds have a specific surface area for adhesion and their structure determines the amount of nutrient supply; therefore, specification of the dose of stem cells is directly related to scaffold design (Zheng et al. 2012). The manufacturer usually reports the optimal number of cells in commercially available scaffolds but in the in vivo research such numbers are estimated from previous in vitro research (Zheng et al. 2012). Based on the studies that were reviewed the main determining factor for the dose of stem cells seemed to be the laboratory procedure of cell seeding onto the scaffolds that varied widely in each study, thus drawing general recommendations is not possible. Overall, $41 \%$ of the evaluated studies reported a range of $10^{6}-10^{7}$ stem cells (Tables 2, 3, 4 and 5).

\section{Co-treatment factors}

Healing promotive factors include a wide variety of growth factors, drugs, bioactive materials, glycosaminoglycans and other small molecules and peptide motifs that may be used with stem cells and scaffolds to enhance the effectiveness of the stem cell therapy on dentine-pulp regeneration and scaffold biocompatibility and biodegradability. Growth factors have a short half-life so should be encapsulated in degradable materials to control their release (Li et al. 2016; Nagaveni et al. 2015). Of the 60 studies evaluated, 23 used no co-administrative factor in combination with stem cells (Tables 2, 3, 4 and 5). Almost half of the studies using a retrograde approach into renal capsule transplantation (63\%) and subcutaneous transplantation (38\%) had assigned no type of co-treatment factor (Tables 2 and 5), whereas in orthograde (regeneration along the full length of the root). approaches, among 13 studies, only 2 (15\%) used nothing (Tables 4 and 5). Generally, treated dentine matrix (TDM) and its soluble proteins were the most popular co-treatment factor. Of 39 studies with a subcutaneous transplantation approach, seven (18\%) used TDM (Table 3). In intracanal studies, these were not popular (only one study) probably because of the existence of natural dentine at the site (Table 5). Of 37 studies that applied co-treatment factors, $6(16 \%)$ used BMPs, 6 used G-CSF (16\%), 3 used SDF-1 $(8.1 \%)$, three $(8 \%)$ used bFGF, and $3(8 \%)$ used VEGF (Tables 2, 3, 4 and 5). These percentages are based on the number of studies with the application of co-treatment factors. Due to the overlap of studies and combination use of co-treatment, the percentages in the pie chart are different, as these are based on the number of co-administrative factor types.

\section{Other related factors}

The impact of age on the capacity of stem cells is a critical aspect of stem cell therapy. Iohara et al. (2014) reported that there was little difference in the regenerative potential of stem cells derived from old or young donors; however, in vivo experiments on canine models reported a $60 \%$ reduction in the volume of the regenerated tissues. On the other hand, while most stem cells are tooth-derived, studies on the impact of tooth maturation on the differentiation capacity of the stem cells has demonstrated that there is a reduced odontogenic, but enhanced osteogenic differentiation capacity the more mature the source (Lei et al. 2011). Finally, laser therapy has biostimulating properties that can assist proliferation of stem cells. Arany et al. (2014) investigated photo-modulation approaches. They reported mineralization and stimulation of stem cells due to the paracrine effect of activated factors and the large area of radiation (Arany et al. 2014). 
The isolation approach for harvesting stem cells can affect their differentiation. In the study of Jeon et al. (2014) on two isolation approaches, an outgrowth method and enzymatic disaggregation, outgrowth SHEDs were more likely to differentiate into hard tissue forming cells while enzymatic disaggregated SHEDs were associated with more colony forming cells, adipogenic differentiation and overall stemness (Jeon et al. 2014).

\section{Time points}

Most of the studies evaluated dentine-pulp regeneration from 4 to 8 weeks after transplantation (Tables 2, 3, 4 and 5). Of the 60 studies, 15 evaluated regeneration after 4 weeks and 16 evaluated regeneration after 8 weeks. Long-term evaluation (more than 20 weeks) was rare and limited to 6 studies (Tables 2, 3, 4 and 5). Those studies that used ectopic models of dentin-pulp complex evaluated the regeneration of the dentin-pulp from 2 to 8 weeks with the most frequent time point being after 8 weeks. Those studies that used true root canal models evaluated the regeneration of the new dentinpulp complex from 2 to 26 weeks after surgery with the most frequent time point being 2 weeks (four studies) or the range of 2-4 weeks (Table 5). Apparently, some studies had multiple time points for their evaluation (Tables 2, 3, 4 and 5).

\section{Assessments}

Before cell transplantation, immunocytochemistry, MTT assay, SEM and flowcytometric analyzes are routinely performed to characterize the transplanting stem cells. To evaluate the regenerating dentine-pulp complex, histology and histomorphometry, immunohistochemistry, and radiology (CT, micro-CT and plain radiography) are the gold standard methods. Histologic slides help to compare the amount of vascularization with the ratio of vessel surface to the entire surface of the slide (Zhang et al. 2015). Of 60 studies evaluated, all used histologic assessments, 36 used immunohistochemistry, 6 used immunofluroscent, 3 used immunostaining, 3 used microCT-scan, 4 used radiography, 4 used SEM and 1 study used MRI to evaluate pulp tissue regeneration (Tables 2, 3, 4 and 5). Immunohistochemistry was much more popular in retrograde studies as 31 from 40 studies with into renal capsule transplantation and subcutaneous transplantation used this method for their assessments (Tables 2 and 3). Radiography was not used in any retrograde studies.

\section{Discussion}

To regenerate a necrotic pulp, just as with other tissues, three main components are needed. Vital cells in the root canal that can differentiate into the natural pulp cells, morphogenic factors to initiate and promote cell differentiation and a matrix that mechanically support the cells and provide an environment to sustain their vitality and proliferation (Galler et al. 2011).

In recent studies, various types of stem cells from various sources in the body have been manipulated for dentine-pulp regeneration (Tables 2, 3, 4 and 5). Dental pulp stem cells are the cell of choice in most of the studies and their capacity for regeneration of the dentine-pulp complex has been demonstrated (Tables 1, 2, 3, 4 and 5). Despite a greater tendency for regeneration of the dentine-pulp complex, administration of SCAP and SHED was rare (all studies that manipulated SCAP and SHED in Tabled 2, 3, 4 and 5 confirm this). Beside dental sources, stem cells from non-dental source such as bone marrow derived mesenchymal stem cells and adipose-derived stem cells were also able to regenerate pulp tissue (Murakami et al. 2015). Generally, each type of adult stem cell seems to be capable of dentine-pulp complex regeneration so that the selected stem cell should be the most feasible to use and the cheapest, especially when the main obstacle in guided tissue regeneration is the cost.

Third molars or any to-be-extracted tooth for orthodontic purposes, and not being extracted because of a microbial infection, are good sources of stem cells. The human body is a rich source of stem cells and they remain in their niches or circulate systemically around the body. In the presence of chemotactic gradients, these cells migrate to the site of injury and participate in the regeneration process, as their potential for migrating to the root canal has demonstrated (Ruangsawasdi et al. 2016; Zhang et al. 2015). In addition, transplanted stem cells may not remain effectively in the site of injury, but migrate elsewhere or go through apoptosis. Such events may be dependent on the type of stem cells, how prone they are to apoptosis, and the structure of the scaffold, which will impact upon the viability of the environment and its influence on stem cells migration. The optimum number of stem cells to be transplanted should be estimated experimentally for each type of stem cell and specific scaffold. However, systemic stem cells can take a role as a backup source. Factors such as SDF-1, SCF and G-CSF help to summon stem cells, and BMSCs particularly are used to demonstrate this in the root canal system (Ruangsawasdi et al. 2016; Takeuchi et al. 2015; Zhang et al. 2015).

Stem cells normally will not differentiate or if they do, they can differentiate to any type of cell. Therefore, their differentiation should be controlled by the means of appropriate growth factors. Soluble proteins of the dentine matrix provide a suitable environment for differentiation of stem cells into odontoblast-like cells while these proteins appear to control the natural differentiation of reparative stem cells. In addition, their position in their locality within dentine, peripheral to the pulp area could help the creation of an odontoblast-like cell lining integrated into 
the dentine wall. Third molars or any to-be-extracted teeth for orthodontic purposes are good source of autogenous dentine matrix. Yet, these matrixes are supposed to be preserved until needed. Freezing makes long-term preservation of human dentine matrix possible as it maintains the mechanical properties of the matrix (Chen et al. 2015b; Jiao et al. 2014).

Regeneration of the dentine-pulp complex relies on sufficient vascularization, which may be limited in the restricted apical region of a canal. Administering growth factors such as VEGF promotes vascularization, but it has a short halflife, so its systemic administration is limited (Li et al. 2016). Binding to heparin is a strategy to make VEGF bioavailable for longer (Li et al. 2016). Apart from locally administering such growth factors, treating stem cells under hypoxic conditions induces cells to secret vascularizing agents (Kuang et al. 2016). Presumably, when cells are in a deficient environment, they would secret a complex of growth factors to overcome the challenge. This type of cell can be used for regeneration purposes and lowers the costs of using purified growth factors.

The scaffolds should have the characteristics to aid in the regeneration of specific tissues. It should have controlled biodegradability to mechanically support the transplants, but not compete spatially with the regenerated tissue. Such controlled biodegradability will be created by a combination of long-term and short-term degradable materials. The proper proportion of this combination should be evaluated experimentally. The scaffold should be porous and spongy to be able to carry sufficient stem cells and growth factors and allow the stream of extracellular matrix and the formation of new blood vessels. As a carrier of growth factors, it should provide controlled release otherwise they will degrade rapidly and thus not take part in long-term regeneration. Binding to heparin can provide this slow release. Silk fibroin scaffold have been used widely in regeneration of tissues such as skin, bone, cartilage, etc., and its efficacy for pulp regeneration has been studied in vivo (Yang et al. 2015a). Treated dentine matrix, other than carrying dentinogenic growth factors, is also applicable as a scaffold (Chen et al. 2015a; Yang et al. 2012). Animal model studies on regeneration of dentine-pulp complex are performed mainly by transplantation of a complex of stem cell, growth factors and scaffolds (C-SGS) into the pulpectomized root canal, which is susceptible to various irritants such as bacteria, masticatory forces, restricted nutritional supply, etc. Therefore, for final approval of novel treatment concepts, intracanal transplantation is necessary. However, as proof of principles for novel studies, C-SGS may be initially transplanted with or without a slice of a tooth subcutaneously or into the renal capsule to evaluate the potential of the novel complex for true regeneration of the dentine-pulp complex regardless of the side effects. This will help track the causes for potential failures and reduce costs in cases where the novel C-SGS proves to be inappropriate.

\section{Conclusion}

It is important to realize that endodontic treatment of teeth with necrotic pulp using stem cells and suitable biomaterials results in pulp regeneration. However, feasibility of stem cell transplantation to treatment sites along with its cost may be obstacles for clinical use of such methods. Scaffolds and biomaterials provide a meaningful approach to better incorporate stem cells and growth factors along with controlled rate of regeneration. Therefore, we recommend future studies to focus on providing a clear guideline for suitable and preferable properties of biomaterials to be used in regenerative endodontics.

Acknowledgement This work was supported by grant from National Institute for Medical Research Development (No:957038)

Funding This study was funded by National Institute for Medical Research Development (NIMAD) (Grant Number: 950738).

\section{Compliance with ethical standards}

Conflict of interest Dr. Hengameh Bakhtiar declares she has no conflicts of interests. Amir Mazidi S declares he has no conflicts of interests. Saeed Mohammadi Asl declares he has no conflicts of interests. Mohammad Reza Ellini declares he has no conflicts of interests. Dr Ali Moshiri declares he has no conflicts of interests. Dr Mohammad Hossein Nekoofar declares he has no conflicts of interests. Prof. Paul MH Dummer declares he has no conflicts of interests.

Ethical approval This article does not include any animal or human studies done by any of the authors.

Open Access This article is distributed under the terms of the Creative Commons Attribution 4.0 International License (http://creativeco mmons.org/licenses/by/4.0/), which permits unrestricted use, distribution, and reproduction in any medium, provided you give appropriate credit to the original author(s) and the source, provide a link to the Creative Commons license, and indicate if changes were made.

\section{References}

Ajay Sharma L, Sharma A, Dias GJ (2015) Advances in regeneration of dental pulp-a literature review. J Investig Clin Dent 6:85-98. https://doi.org/10.1111/jicd.12064

Aksel H, Serper A (2014) Recent considerations in regenerative endodontic treatment approaches. J Dent Sci 9:207-213. https://doi. org/10.1016/j.jds.2013.12.007

Alongi DJ et al (2010) Stem/progenitor cells from inflamed human dental pulp retain tissue regeneration potential. Regen Med 5:617631. https://doi.org/10.2217/rme.10.30 
Arany PR et al (2014) Photoactivation of endogenous latent transforming growth factor-beta1 directs dental stem cell differentiation for regeneration. Sci Transl Med 6:238ra269. https://doi.org/10.1126/ scitranslmed.3008234

Asatrian G, Pham D, Hardy WR, James AW, Peault B (2015) Stem cell technology for bone regeneration: current status and potential applications Stem Cells. Cloning 8:39-48. https://doi.org/10.2147/ SCCAA.S48423

Atalayin C, Tezel H, Dagci T, Karabay Yavasoglu NU, Oktem G, Kose $\mathrm{T}$ (2016) In vivo performance of different scaffolds for dental pulp stem cells induced for odontogenic differentiation. Braz Oral Res 30:e120. https://doi.org/10.1590/1807-3107BOR-2016.vol30 .0120

Bakhtiar H, Mirzaei H, Bagheri MR, Fani N, Mashhadiabbas F, Baghaban Eslaminejad M, Sharifi D, Nekoofar MH, Dummer P (2017) Histologic tissue response to furcation perforation repair using mineral trioxide aggregate or dental pulp stem cells loaded onto treated dentin matrix or tricalcium phosphate. Clin Oral Investig 21(5):1579-1588

Bakhtiar H, Esmaeili S, Fakhr Tabatabayi S, Ellini MR, Nekoofar MH, Dummer PM (2017) Second-generation Platelet Concentrate (Platelet-rich Fibrin) as a Scaffold in Regenerative Endodontics: a case series

Barry FP (2003) Biology and clinical applications of mesenchymal stem cells. Birth Defects Res C Embryo Today 69:250-256. https ://doi.org/10.1002/bdrc.10021

Brar GS, Toor RS (2012) Dental stem cells: dentinogenic, osteogenic, and neurogenic differentiation and its clinical cell based therapies. Indian J Dent Res 23:393-397. https://doi.org/10.4103/09709290.102239

Cao $\mathrm{Y}$ et al (2015) Adenovirus-mediated transfer of hepatocyte growth factor gene to human dental pulp stem cells under good manufacturing practice improves their potential for periodontal regeneration in swine. Stem Cell Res Ther 6:249. https://doi.org/10.1186/ s13287-015-0244-5

Casagrande L, Cordeiro MM, Nor SA, Nor JE (2011) Dental pulp stem cells in regenerative dentistry. Odontology 99:1-7. https://doi. org/10.1007/s10266-010-0154-z

Chan BP, Leong KW (2008) Scaffolding in tissue engineering: general approaches and tissue-specific considerations. Eur Spine J 17(Suppl 4):467-479. https://doi.org/10.1007/s00586-008-0745-3

Chen B, Sun HH, Wang HG, Kong H, Chen FM, Yu Q (2012) The effects of human platelet lysate on dental pulp stem cells derived from impacted human third molars. Biomaterials 33:5023-5035. https://doi.org/10.1016/j.biomaterials.2012.03.057

Chen $\mathrm{G}$ et al (2015a) Combination of aligned PLGA/Gelatin electrospun sheets, native dental pulp extracellular matrix and treated dentin matrix as substrates for tooth root regeneration. Biomaterials 52:56-70. https://doi.org/10.1016/j.biomaterials.2015.02.011

Chen $\mathrm{G}$ et al (2015b) Comparison of the odontogenic differentiation potential of dental follicle, dental papilla, and cranial neural crest cells. J Endod 41:1091-1099. https://doi.org/10.1016/j. joen.2015.03.003

Chen Y et al (2015c) Human umbilical cord mesenchymal stem cells: a new therapeutic option for tooth regeneration. Stem cells Int 2015:549432. https://doi.org/10.1155/2015/549432

Chen Z et al (2015d) Biomimetic remineralization of demineralized dentine using scaffold of CMC/ACP nanocomplexes in an in vitro tooth model of deep caries. PLoS One 10:e0116553. https://doi. org/10.1371/journal.pone.0116553

Chong JJH, Murry CE (2014) Cardiac regeneration using pluripotent stem cells-progression to large animal models. Stem Cell Res 13:654-665. https://doi.org/10.1016/j.scr.2014.06.005

Dellavalle A, Maroli G, Covarello D, Azzoni E, Innocenzi A, Perani L, Antonini S, Sambasivan R, Brunelli S, Tajbakhsh c, Cossu G
(2011) Pericytes resident in postnatal skeletal muscle differentiate into muscle fibres and generate satellite cells. Nat Commun 2:499

Devolder K (2010) Complicity in stem cell research: the case of induced pluripotent stem cells. Hum Reprod 25:2175-2180

Dissanayaka WL, Zhu L, Hargreaves KM, Jin L, Zhang C (2014) Scaffold-free prevascularized microtissue spheroids for pulp regeneration. J Dent Res 93:1296-1303. https://doi.org/10.1177/00220 34514550040

Dissanayaka WL, Hargreaves KM, Jin L, Samaranayake LP, Zhang C (2015) The interplay of dental pulp stem cells and endothelial cells in an injectable peptide hydrogel on angiogenesis and pulp regeneration in vivo. Tissue Eng Part A 21:550-563. https://doi. org/10.1089/ten.TEA.2014.0154

Egusa H, Sonoyama W, Nishimura M, Atsuta I, Akiyama K (2012) Stem cells in dentistry-Part I: stem cell sources. J Prosthodont Res 56:151-165. https://doi.org/10.1016/j.jpor.2012.06.001

Eslaminejad MB, Nadri S, Hosseini RH (2007) Expression of Thy 1.2 surface antigen increases significantly during the murine mesenchymal stem cells cultivation period. Dev Growth Diff 49:351364. https://doi.org/10.1111/j.1440-169X.2007.00932.x

Fakhr Tabatabayi S, Bakhtiar H, Vatanpour M, Honarvar M (2015) Apical closure in a necrotic immature tooth by Revascularization therapy using Platelet-Rich Fibrin: a case report. Res Dent Sci 11:242-246

Galler KM, D’Souza RN, Federlin M, Cavender AC, Hartgerink JD, Hecker S, Schmalz G (2011) Dentin conditioning codetermines cell fate in regenerative endodontics. J Endod 37:1536-1541. https ://doi.org/10.1016/j.joen.2011.08.027

Gao ZH, Hu L, Liu GL, Wei FL, Liu Y, Liu ZH, Fan ZP, Zhang CM, Wang JS, Wang SL (2016) Bio-Root and implant-based restoration as a tooth replacement alternative. J Dent Res 95(6):642-649

Goldberg M (2011) Pulp healing and regeneration: more questions than answers. Adv Dent Res 23:270-274. https://doi. org/10.1177/0022034511405385

Gong T, Heng BC, Lo EC, Zhang C (2016) Current advance and future prospects of tissue engineering approach to dentin/pulp regenerative therapy. Stem Cells Int 2016:9204574. https://doi org/10.1155/2016/9204574

Hashmi B et al (2017) Mechanical induction of dentin-like differentiation by adult mouse bone marrow stromal cells using compressive scaffolds. Stem Cell Res 24:55-60. https://doi.org/10.1016/j. scr.2017.08.011

Hilkens P et al (2014) Pro-angiogenic impact of dental stem cells in vitro and in vivo. Stem Cell Res 12:778-790. https://doi. org/10.1016/j.scr.2014.03.008

Hilkens P, Meschi N, Lambrechts P, Bronckaers A, Lambrichts I (2015) Dental stem cells in pulp regeneration: near future or long road ahead? Stem Dec 24:1610-1622. https://doi.org/10.1089/ scd.2014.0510

Hilkens P, Bronckaers A, Ratajczak J, Gervois P, Wolfs E, Lambrichts I (2017) The angiogenic potential of DPSCs and SCAPs in an in vivo model of dental pulp regeneration. Stem Cells Int 2017:2582080. https://doi.org/10.1155/2017/2582080

Horibe $\mathrm{H}$ et al (2014) Isolation of a stable subpopulation of mobilized dental pulp stem cells (MDPSCs) with high proliferation, migration, and regeneration potential is independent of age. PLoS One 9:e98553. https://doi.org/10.1371/journal.pone.0098553

Huang GT, Yamaza T, Shea LD, Djouad F, Kuhn NZ, Tuan RS, Shi S (2010) Stem/progenitor cell-mediated de novo regeneration of dental pulp with newly deposited continuous layer of dentin in an in vivo model. Tissue Eng Part A 16:605-615. https://doi. org/10.1089/ten.TEA.2009.0518

Hung CN et al (2011) A comparison between adipose tissue and dental pulp as sources of MSCs for tooth regeneration. Biomaterials 32:6995-7005. https://doi.org/10.1016/j.biomaterials.2011.05.086 
Huo N et al (2010) Differentiation of dermal multipotent cells into odontogenic lineage induced by embryonic and neonatal tooth germ cell-conditioned medium. Stem Cells Dev 19:93-104. https ://doi.org/10.1089/scd.2009.0048

Ikeda E et al (2009) Fully functional bioengineered tooth replacement as an organ replacement therapy. Proc Natl Acad Sci USA 106:13475-13480. https://doi.org/10.1073/pnas.0902944106

Iohara $\mathrm{K}$ et al (2011) Complete pulp regeneration after pulpectomy by transplantation of CD105+ stem cells with stromal cellderived factor-1. Tissue Eng Part A 17:1911-1920. https://doi. org/10.1089/ten.TEA.2010.0615

Iohara K et al (2013) A novel combinatorial therapy with pulp stem cells and granulocyte colony-stimulating factor for total pulp regeneration. Stem Cells Transl Med 2:521-533. https://doi. org/10.5966/sctm.2012-0132

Iohara K, Murakami M, Nakata K, Nakashima M (2014) Agedependent decline in dental pulp regeneration after pulpectomy in dogs. Exp Gerontol 52:39-45. https://doi.org/10.1016/j.exger .2014.01.020

Ishizaka R et al (2013) Stimulation of angiogenesis, neurogenesis and regeneration by side population cells from dental pulp. Biomaterials 34:1888-1897. https://doi.org/10.1016/j.biomateria 1s.2012.10.045

Jeon M, Song JS, Choi BJ, Choi HJ, Shin DM, Jung HS, Kim SO (2014) In vitro and in vivo characteristics of stem cells from human exfoliated deciduous teeth obtained by enzymatic disaggregation and outgrowth. Arch Oral Biol 59:1013-1023. https:// doi.org/10.1016/j.archoralbio.2014.06.002

Jiang N et al (2014) Postnatal epithelium and mesenchyme stem/progenitor cells in bioengineered amelogenesis and dentinogenesis. Biomaterials 35:2172-2180. https://doi.org/10.1016/j.biomateria 1s.2013.11.061

Jiao L et al (2014) Cryopreserved dentin matrix as a scaffold material for dentin-pulp tissue regeneration. Biomaterials 35:4929-4939. https://doi.org/10.1016/j.biomaterials.2014.03.016

Jin B, Choung PH (2016) Recombinant human plasminogen activator inhibitor-1 accelerates odontoblastic differentiation of human stem cells from apical papilla. Tissue Eng Part A 22:721-732. https:// doi.org/10.1089/ten.tea.2015.0273

Kawamura R, Hayashi Y, Murakami H, Nakashima M (2016) EDTA soluble chemical components and the conditioned medium from mobilized dental pulp stem cells contain an inductive microenvironment, promoting cell proliferation, migration, and odontoblastic differentiation. Stem Cell Res Ther 7:77. https://doi. org/10.1186/s13287-016-0334-z

Kodonas K, Gogos C, Papadimitriou S, Kouzi-Koliakou K, Tziafas D (2012) Experimental formation of dentin-like structure in the root canal implant model using cryopreserved swine dental pulp progenitor cells. J Endod 38:913-919. https://doi.org/10.1016/j. joen.2012.02.005

Kuang R, Zhang Z, Jin X, Hu J, Shi S, Ni L, Ma PX (2016) Nanofibrous spongy microspheres for the delivery of hypoxia-primed human dental pulp stem cells to regenerate vascularized dental pulp. Acta Biomater 33:225-234. https://doi.org/10.1016/j.actbi o.2016.01.032

Lei $\mathrm{G}$ et al (2011) Dentinogenic capacity: immature root papilla stem cells versus mature root pulp stem cells. Biol Cell 103:185-196. https://doi.org/10.1042/bc20100134

Lei $\mathrm{G}$ et al (2013) Differentiation of BMMSCs into odontoblast-like cells induced by natural dentine matrix. Arch Oral Biol 58:862870. https://doi.org/10.1016/j.archoralbio.2013.01.002

Lei M, Li K, Li B, Gao LN, Chen FM, Jin Y (2014) Mesenchymal stem cell characteristics of dental pulp and periodontal ligament stem cells after in vivo transplantation. Biomaterials 35:6332-6343. https://doi.org/10.1016/j.biomaterials.2014.04.071
Li X, Ma C, Xie X, Sun H, Liu X (2016) Pulp regeneration in a fulllength human tooth root using a hierarchical nanofibrous microsphere system. Acta Biomater 35:57-67

Liu H, Cao T (2010) Dental application potential of mesenchymal stromal cells and embryonic stem cells Chin. J Dent Res 13:95-103

Ma L et al (2012) Cryopreserved dental pulp tissues of exfoliated deciduous teeth is a feasible stem cell resource for regenerative medicine. PLoS One 7:e51777. https://doi.org/10.1371/journ al.pone. 0051777

Murakami M, Hayashi Y, Iohara K, Osako Y, Hirose Y, Nakashima M (2015) Trophic effects and regenerative potential of mobilized mesenchymal stem cells from bone marrow and adipose tissue as alternative cell sources for pulp/dentin regeneration. Cell Transpl 24:1753-1765. https://doi.org/10.3727/096368914X683502

Murray PE, Garcia-Godoy F, Hargreaves KM (2007) Regenerative endodontics: a review of current status and a call for action. J Endod 33:377-390. https://doi.org/10.1016/j.joen.2006.09.013

Na S, Zhang H, Huang F, Wang W, Ding Y, Li D, Jin Y (2013) Regeneration of dental pulp/dentine complex with a three-dimensional and scaffold-free stem-cell sheet-derived pellet. J Tissue Eng Regen Med. https://doi.org/10.1002/term.1686

Nagaveni N, Kumari K, Poornima P, Reddy V (2015) Management of an endo-perio lesion in an immature tooth using autologous platelet-rich fibrin: a case report. 33. https://doi.org/10.4103/09704388.149013

Nuti N, Corallo C, Chan BM, Ferrari M, Gerami-Naini B (2016) Multipotent differentiation of human dental pulp stem cells: a literature review. Stem Cell Rev. https://doi.org/10.1007/s1201 5-016-9661-9

Pan S et al (2013) SCF promotes dental pulp progenitor migration, neovascularization, and collagen remodeling - potential applications as a homing factor in dental pulp regeneration. Stem Cell Rev 9:655-667. https://doi.org/10.1007/s12015-013-9442-7

Reynolds BA, Weiss S (1992) Generation of neurons and astrocytes from isolated cells of the adult mammalian central nervous system science 255:1707-1710

Rimondini L, Mele S (2009) Stem cell technologies for tissue regeneration in dentistry. Miner Stomatol 58:483-500

Rodriguez-Lozano FJ et al (2012) Mesenchymal dental stem cells in regenerative dentistry. Med Oral Patol Oral Cir Bucal 17:e1062-1067

Ruangsawasdi N, Zehnder M, Patcas R, Ghayor C, Siegenthaler B, Gjoksi B, Weber FE (2016) Effects of stem cell factor on cell homing during functional pulp regeneration in human immature teeth. Tissue Eng Part A. https://doi.org/10.1089/ten.TEA.2016.0227

Schmalz G, Smith AJ (2014) Pulp development, repair, and regeneration: challenges of the transition from traditional dentistry to biologically based therapies. J Endod 40:S2-5. https://doi. org/10.1016/j.joen.2014.01.018

Sharma S, Srivastava D, Grover S, Sharma V (2014) Biomaterials in tooth tissue engineering: a review J Clin Diagn Res 8:309-315. https://doi.org/10.7860/JCDR/2014/7609.3937

Shi S, Bartold PM, Miura M, Seo BM, Robey PG, Gronthos S (2005) The efficacy of mesenchymal stem cells to regenerate and repair dental structures. Orthod Craniofac Res 8:191-199. https://doi. org/10.1111/j.1601-6343.2005.00331.x

Stolzing A, Jones E, McGonagle D, Scutt A (2008) Age-related changes in human bone marrow-derived mesenchymal stem cells: consequences for cell therapies. Mech Ageing Dev 129:163-173. https://doi.org/10.1016/j.mad.2007.12.002

Takeuchi $\mathrm{N}$ et al (2015) Similar in vitro effects and pulp regeneration in ectopic tooth transplantation by basic fibroblast growth factor and granulocyte-colony stimulating factor. Oral Dis 21:113-122. https://doi.org/10.1111/odi.12227

Tran Hle B, Doan VN (2015) Human dental pulp stem cells cultured onto dentin derived scaffold can regenerate dentin-like tissue 
in vivo. Cell Tissue Bank 16:559-568. https://doi.org/10.1007/ s10561-015-9503-Z

Wang J, Ma H, Jin X, Hu J, Liu X, Ni L, Ma PX (2011a) The effect of scaffold architecture on odontogenic differentiation of human dental pulp stem cells. Biomaterials 32:7822-7830. https://doi. org/10.1016/j.biomaterials.2011.04.034

Wang YX, Ma ZF, Huo N, Tang L, Han C, Duan YZ, Jin Y (2011b) Porcine tooth germ cell conditioned medium can induce odontogenic differentiation of human dental pulp stem cells. J Tissue Eng Regen Med 5:354-362. https://doi.org/10.1002/term.321

Wang X et al (2012) Comparative characterization of stem cells from human exfoliated deciduous teeth and dental pulp stem cells. Arch Oral Biol 57:1231-1240. https://doi.org/10.1016/j.archoralbio.2012.02.014

Wang L et al (2013) Proliferation and osteo/odontoblastic differentiation of stem cells from dental apical papilla in mineralizationinducing medium containing additional $\mathrm{KH}(2) \mathrm{PO}(4)$. Cell Prolif 46:214-222. https://doi.org/10.1111/cpr.12016

Wang W, Dang M, Zhang Z, Hu J, Eyster TW, Ni L, Ma PX (2016) Dentin regeneration by stem cells of apical papilla on injectable nanofibrous microspheres and stimulated by controlled BMP-2 release. Acta Biomater 36:63-72. https://doi.org/10.1016/j.actbi o.2016.03.015

Wei $\mathrm{F}$ et al (2013) Functional tooth restoration by allogeneic mesenchymal stem cell-based bio-root regeneration in swine. Stem Cells Dev 22:1752-1762. https://doi.org/10.1089/scd.2012.0688

Yadlapati M et al (2017) Characterization of a vascular endothelial growth factor-loaded bioresorbable delivery system for pulp regeneration. J Endod 43:77-83. https://doi.org/10.1016/j. joen.2016.09.022

Yan M et al (2014) Mineral trioxide aggregate promotes the odonto/ osteogenic differentiation and dentinogenesis of stem cells from apical papilla via nuclear factor kappa B signaling pathway. J Endod 40:640-647. https://doi.org/10.1016/j.joen.2014.01.042

Yang X, Han G, Pang X, Fan M (2012) Chitosan/collagen scaffold containing bone morphogenetic protein-7 DNA supports dental pulp stem cell differentiation in vitro and in vivo. J Biomed Mater Res A. https://doi.org/10.1002/jbm.a.34064

Yang JW, Zhang YF, Sun ZY, Song GT, Chen Z (2015a) Dental pulp tissue engineering with bFGF-incorporated silk fibroin scaffolds. J Biomater Appl 30:221-229. https://doi.org/10.1177/0885328215577296

Yang JW et al (2015b) Autophagy in SDF-1alpha-mediated DPSC migration and pulp regeneration. Biomaterials 44:11-23. https:// doi.org/10.1016/j.biomaterials.2014.12.006

Zhang LX et al (2015) Systemic BMSC homing in the regeneration of pulp-like tissue and the enhancing effect of stromal cell-derived factor-1 on BMSC homing Int J. Clin Exp Pathol 8:10261-10271

Zhang M, Jiang F, Zhang X, Wang S, Jin Y, Zhang W, Jiang X (2017) The effects of platelet-derived growth factor-BB on human dental pulp stem cells mediated dentin-pulp complex regeneration. Stem cells Transl Med. https://doi.org/10.1002/sctm.17-0033

Zheng L et al (2011) The effect of composition of calcium phosphate composite scaffolds on the formation of tooth tissue from human dental pulp stem cells. Biomaterials 32:7053-7059. https://doi. org/10.1016/j.biomaterials.2011.06.004

Zheng Y, Wang XY, Wang YM, Liu XY, Zhang CM, Hou BX, Wang SL (2012) Dentin regeneration using deciduous pulp stem/progenitor cells. J Dent Res 91:676-682. https://doi.org/10.1177/00220 34512449834

Publisher's Note Springer Nature remains neutral with regard to jurisdictional claims in published maps and institutional affiliations. 